\title{
Influence of light-exposure methods and depths of cavity on the microhardness of dual-cured core build-up resin composites
}

\author{
Keiichi YOSHIDA ${ }^{1}$, Xiangfeng MENG ${ }^{2}$
}

1- Clinic of Fixed Prosthodontics, Nagasaki University Hospital, Nagasaki, Japan.

2- Department of Prosthodontics, The Stomatological Hospital Affiliated Medical School, Nanjing University, Nanjing, China.

Corresponding address: Keiichi Yoshida - Clinic of Fixed Prosthodontics - Nagasaki University Hospital, 1-7-1 - Sakamoto, - Nagasaki - $852-8588$ - Japan - Phone: +81-95-819-7688 - Fax: +81-95-819-7689 - e-mail: keiichi@nagasaki-u.ac.jp

Submitted: May 26, 2013 - Modification: August 19, 2013 - Accepted: September 18, 2013

\section{ABSTRACT}

\begin{abstract}
bjective: The purpose of this study was to evaluate the Knoop hardness number (KHN) of dual-cured core build-up resin composites (DCBRCs) at 6 depths of cavity after 3 post-irradiation times by 4 light-exposure methods. Material and Methods: Five specimens each of DCBRCs (Clearfil DC Core Plus [DCP] and Unifil Core EM [UCE]) were filled in acrylic resin blocks with a semi-cylindrical cavity and light-cured using an LED light unit (power density: 1,000 $\mathrm{mW} / \mathrm{cm}^{2}$ ) at the top surface by irradiation for 20 seconds (20 s), 40 seconds (40 s), bonding agent plus 20 seconds ( $B+20 \mathrm{~s})$, or 40 seconds plus light irradiation of both sides of each acrylic resin block for 40 seconds each (120 s). KHN was measured at depths of $0.5,2.0,4.0,6.0,8.0$, and $10.0 \mathrm{~mm}$ at 0.5 hours, 24 hours, and 7 days post-irradiation. Statistical analysis was performed using repeated measures ANOVA and Tukey's compromise post-hoc test with a significance level of $p<0.05$. Results: For both DCBRCs, at 0.5 hours post-irradiation, the $20 \mathrm{~s}$ and $40 \mathrm{~s}$ methods showed the highest KHN at depth of $0.5 \mathrm{~mm}$. The $40 \mathrm{~s}$ method showed significantly higher KHN than the $20 \mathrm{~s}$ method at all depths of cavity and post-irradiation times, except UCE at depth of $0.5 \mathrm{~mm}(\mathrm{p}<0.05)$. The $120 \mathrm{~s}$ method did not result in significantly different KHN at all depths of cavity and post-irradiation times ( $p>0.05)$. In DCP, and not UCE, at 24 hours and 7 days post-irradiation, the $\mathrm{B}+20 \mathrm{~s}$ method showed significantly higher $\mathrm{KHN}$ at all depths of cavity, except the depth of $0.5 \mathrm{~mm}(\mathrm{p}<0.05)$. Conclusion: KHN depends on the light-exposure method, use of bonding agent, depth of cavity, post-irradiation time, and material brand. Based on the microhardness behavior, DCBRCs are preferably prepared by the effective exposure method, when used for a greater depth of cavity.
\end{abstract}

Keywords: Composite resins. Exposure time. Hardness.

\section{INTRODUCTION}

Core build-up materials are often required to reconstruct and provide an ideal morphology to severely damaged teeth prior to their preparation for indirect foundation restorations. Despite substantial documented evidence of the long-term success of large amalgam restorations ${ }^{26,40}$, resin composites, since the early days of self-cured materials, have also been used for this purpose. More recently, light-cured core build-up materials that are more convenient to use than chemically cured composites have been widely used ${ }^{33}$. Both these materials, however, have their disadvantages ${ }^{12,29}$. While chemically cured materials do not allow clinicians to adjust the setting time individually, light-cured resin composites do not ensure adequate polymerization in areas with limited access to the curing light.

However, resin-based composites are associated with polymerization shrinkage, causing stress development under confined conditions ${ }^{36}$. Several strategies have been used to overcome the limitations of polymerization shrinkage. Various layering techniques have been suggested to minimize shrinkage stress ${ }^{20,23}$. Nevertheless, time limitations when placing core build-up materials 
restrict clinicians from using elaborate multilayering techniques. Therefore, dual-cured resin composites, in which polymerization is chemically initiated in the deeper portions of the canal or preparations, have been developed for use as core build-up materials; this has allowed clinicians to build extended foundation restorations quickly, and in bulk.

At the coronal region, dual-cured core build-up resin composites are mainly polymerized through photo-initiated reactions, whereas, in the apical region, polymerization is chemically initiated. However, the incorporation of self- and light-curing modes in the same material does not ensure maximal curing of the material. Due to incomplete compensation for deficient light activation, lower hardness values of dual-cured core build-up resin composites have been observed with increased depth of cavity ${ }^{1}$. It has been speculated that a delay in light activation would be beneficial in enhancing the degree of conversion of dual-cured resin cements, since immediate exposure to light could interfere with the chemical-curing mechanism ${ }^{24}$. On the other hand, it has been reported that time delay and duration of light exposure does not increase microhardness at different depths of a dual-cured core build-up resin composite 2 weeks after light irradiation ${ }^{39}$. Moreover, light-activation delayed by 5 minutes after seating the fiber-reinforced post did not affect the microhardness of dual-cured resin cements at 3 regions of the root after 3 months of storage in water ${ }^{28}$. Although dual-cured core build-up resin composites have been recently used to prepare prefabricated posts and core or coronalradicular build-ups, their hardness behavior at greater depths of cavity is unknown. Moreover, no information is available in the literature regarding the effect of applying a bonding agent on the cavity wall on polymerization of the dual-cured core buildup resin composite.

Based on these considerations, the purpose of the present study was to investigate the influence of light-exposure durations (20, 40, and 120 seconds) and application of a bonding agent on the extent of polymerization by measuring the microhardness of 2 dual-cured core build-up resin composites at different depths of cavity without prefabricated posts and various post-irradiation times. The following null hypotheses were tested: (1) an increase in light-exposure time results in no difference in hardness, regardless of the depth of cavity and type of dual-cured resin composite; (2) hardness is not affected by depth of cavity and post-irradiation time; and (3) application of the bonding agent does not improve hardness.

\section{MATERIAL AND METHODS}

\section{Specimen preparation}

Forty semi-cylindrical cavities with a diameter of $3 \mathrm{~mm}$ and a depth of $11 \mathrm{~mm}$ were prepared in $5 \times 10 \times 16 \mathrm{~mm}$ acrylic resin blocks (Figure 1). Two acrylic resin blocks, with or without a semicylindrical cavity, were placed in a silicon impression material mold ( $15 \times 15 \times 20 \mathrm{~mm})$. Either 1 of 2 dualcured core build-up resin composite pastes [Clearfil DC Core Plus (DCP) or Unifil Core EM (UCE) (Figure 2)] was filled directly in the cavities using automixing tips, being sure to avoid entrapment of air, according to the manufacturer's instructions. The upper surface in the resin composite material was covered with a plastic strip and pressed with a thin cover glass to remove any excess resin. Light-irradiation was provided by placing the tip of the LED light unit (power density: 1,000 mW/ $\mathrm{cm}^{2}$; Pencure, J. Morita MFG Corp., Kyoto, Japan) on the plastic strip. Power output was verified with a curing radiometer (Cure Lite; Dentsply Caulk, Milford, CT, USA) immediately before every lightactivation throughout the study. The core build-up resin composites were light-cured for different durations using 1 of the 4 following light-exposure methods: (1) light-irradiation for 20 seconds on the plastic strip after filling the core build-up resin composite (20 s method); (2) light-irradiation for 40 seconds (40 s); (3) application of the bonding agent on the cavity wall with a brush, followed by air-drying, and light-irradiation for 10 seconds on the top of the cavity before the $20 \mathrm{~s}$ method $(B+20$ $s$ method); (4) light-irradiation for 40 seconds on the plastic strip, followed by removal of the acrylic blocks from the silicon impression material mold, and irradiation of both sides of each acrylic resin block for 40 seconds each (120 s method). After irradiation of all the specimens, the acrylic resin blocks were removed from the silicon mold and separated. Five specimens of each dual-cured core build-up resin composite were irradiated by each of the 4 methods.

\section{Hardness measurements}

Hardness was measured at the following depths from the light-irradiated surface of the cavity: $0.5,2.0,4.0,6.0,8.0$, and $10.0 \mathrm{~mm}$. For each specimen, the Knoop hardness number (KHN) was measured 5 times at each depth using a microhardness tester (FM-700: Future-Tech Corp., Kawasaki, Japan) at 0.5 hours, 24 hours, and 7 days post-irradiation. A Knoop diamond indenter was applied under a load of $25 \mathrm{~g}$ for a dwell time of 15 seconds; the load was then removed, and the long diagonal of the indentation was measured under 400x magnification. KHN, which is inversely proportional to the square of the long diagonal, 
a
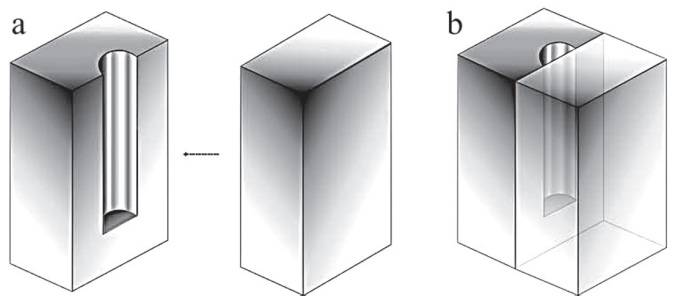
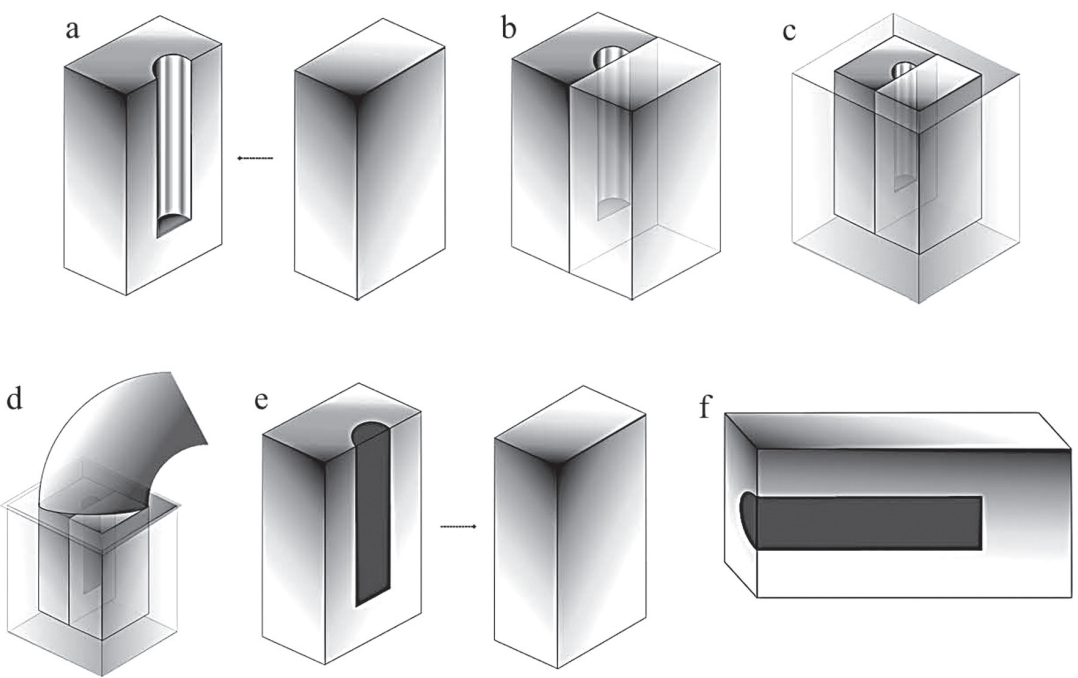

Figure 1- Schematic illustration of the preparation of specimens for measurement of Knoop hardness: a: acrylic resin blocks (5x10x16 mm) with or without semi-cylindrical cavity (diameter of $3 \mathrm{~mm}$ and depth of $11 \mathrm{~mm}$ ); b: two acrylic resin

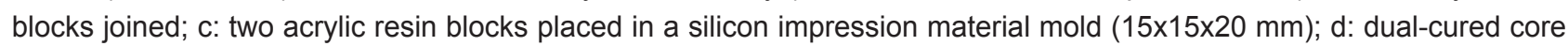
build-up resin composite filled in the cavity and irradiated on the upper surface using LED light unit; e: two acrylic resin blocks separated; f: Knoop hardness measurement for the surface of resin composite filled in the semi-cylindrical cavity

\begin{tabular}{|c|c|c|}
\hline Materials & Manufacturer & Composition \\
\hline \multicolumn{3}{|l|}{ Core material } \\
\hline \multirow[t]{2}{*}{ (Batch \# 0002AA) } & $\begin{array}{l}\text { Kuraray Noritake Products } \\
\text { Corp., Tokyo, Japan }\end{array}$ & $\begin{array}{l}\text { A paste: Bis-GMA, hydrophilic aliphatic dimethacrylate, } \\
\text { hydrophobic aliphatic dimethacrylate,hydrophobic } \\
\text { aromatic dimethacrylate, silanized barium glass filler, } \\
\text { silanized colloidal silica, colloidal silica, chemical-initiator, } \\
\text { photo-initiator, pigments }\end{array}$ \\
\hline & & $\begin{array}{c}\text { B paste: TEGDMA, hydrophilic aliphatic dimethacrylate, } \\
\text { hydrophobic aromatic dimethacrylate, silanized barium } \\
\text { glass filler, silanized colloidal silica, aluminum oxide filler, } \\
\text { photo-accelerator , chemical-accelerator }\end{array}$ \\
\hline \multicolumn{3}{|l|}{ Bonding material } \\
\hline $\begin{array}{l}\text { Clearfil S³ Bond Plus } \\
\text { (Batch \# 00024B) }\end{array}$ & $\begin{array}{l}\text { Kuraray Noritake Products } \\
\text { Corp., Tokyo, Japan }\end{array}$ & $\begin{array}{l}\text { Bis-GMA,HEMA, MDP, hydrophilic dimethacrylate, } \\
\text { hydrophobic dimethacrylate, colloidal silica, ethanol, } \\
\text { water, photo-initiators, photo- and chemical-accelerator, } \\
\text { sodium fluoride }\end{array}$ \\
\hline \multicolumn{3}{|l|}{ Core material } \\
\hline \multirow[t]{2}{*}{$\begin{array}{l}\text { Unifil Core EM (UCE) } \\
\text { (Batch \# 1107011) }\end{array}$} & GC Corp., Tokyo, Japan & $\begin{array}{l}\text { Base: UDMA, dimethacrylates, fluoro-alumino-silicate } \\
\text { glass, silicon dioxide, photo-initiator, accelerator }\end{array}$ \\
\hline & & $\begin{array}{c}\text { Catalyst: UDMA, dimethacrylates, fluoro-alumino-silicate } \\
\text { glass, silicon dioxide, chemical-initiator, pigment }\end{array}$ \\
\hline \multicolumn{3}{|l|}{ Bonding material } \\
\hline $\begin{array}{l}\text { Self-etching bond A } \\
\text { (Batch \# 1205181) }\end{array}$ & GC Corp., Tokyo, Japan & $\begin{array}{l}\text { dimethacrylates, 4-META, silicon dioxide, ethanol, water, } \\
\text { photo-initiator }\end{array}$ \\
\hline $\begin{array}{c}\text { Self-etching bond B } \\
\text { (Batch \# 1206011) }\end{array}$ & GC Corp., Tokyo, Japan & ethanol, accelerator \\
\hline
\end{tabular}

Bis-GMA: bis-phenol-A-glycidyldimethacrylate; TEGDMA: triethyleneglycol dimethacrylate; UDMA: urethane dimethacrylate; HEMA: 2-hydoxyethyl methacrylate; MDP: 10-methacryloyloxydecyl dihydrogen phosphate; 4-META: 4-methacryloyloxyethyl trimellitate anhydride

Figure 2- Dual-cured core build-up resin composites used in this study 
was thus calculated. All specimens were stored under dry and dark conditions in a box, which was placed in a biochemical incubator at $37^{\circ} \mathrm{C}$ to avoid exposure to light, and was accessed only to obtain measurements.

\section{Statistical analysis}

The KHN data were statistically analyzed by the repeated measures three-way ANOVA test. The independent variables analyzed were depths of cavity and post-irradiation times for within-subject analysis, and light-exposure methods and type of dual-cured core build-up resin composite for between-subject analysis. A one-way ANOVA with the post-hoc Tukey's compromise test was used to establish specific differences in KHN values between the groups ( $\alpha=0.05)$.

\section{RESULTS}

The results of this study are summarized in Tables 1 and 2, which show the mean KHN and standard deviation of all the experimental groups in DCP and UCE, respectively, at 6 depths of cavity after 3 different post-irradiation durations by 4 different light-exposure methods.

For the DCP, the KHN was effected by the light-exposure method ( $p=0.0001 ; F=1652.29)$, post-irradiation time $(p=0.0001 ; F=606.09)$, depth of cavity $(p=0.0001 ; F=1184.99)$, and all the interactions between all the aforementioned factors $(p=0.0001)$. For UCE, significant differences were found between the light-exposure methods $(p=0.0001 ; F=201.27)$, post-irradiation times $(p=0.0001 ; F=857.15)$, and depth of cavity $(p=0.0001 ; F=488.76)$; in addition, significant interactions were also found between all the aforementioned factors $(p=0.0001)$.

For both resin composites, at 0.5 hours postirradiation, the $20 \mathrm{~s}$ and $40 \mathrm{~s}$ methods resulted in the highest KHN values at the depth of $0.5 \mathrm{~mm}$; these values gradually decreased with increasing depths of cavity $(p<0.05)$. On the other hand, at 24 hours or 7 days post-irradiation, the KHN values of DCP or UCE were not significantly different between the depths of $2.0 \mathrm{~mm}, 4.0 \mathrm{~mm}$, and/or $6.0 \mathrm{~mm}$, or $8.0 \mathrm{~mm}$ and $10.0 \mathrm{~mm}$, respectively ( $p>0.05)$.

The $40 \mathrm{~s}$ method resulted in significantly higher $\mathrm{KHN}$ values than the $20 \mathrm{~s}$ method at all depths of cavity and post-irradiation times for both resin composites, with the exception of UCE at the depth of $0.5 \mathrm{~mm}(p<0.05)$. With the $120 \mathrm{~s}$ method, the $\mathrm{KHN}$ values of both resin composites were not significantly different among the 6 depths of cavity at all post-irradiation times $(p>0.05)$, but they were significantly higher than those of the $40 \mathrm{~s}$ method, with the exception of that at the depth of $0.5 \mathrm{~mm}$ at all post-irradiation times $(\mathrm{p}<0.05)$.

Table 1- Mean KHN \pm SD for Clearfil DC Core Plus (DCP) at 6 depths of cavity after 3 post-irradiation times by 4 lightexposure methods

The same lower-case superscript Greek characters indicate no statistically significant differences between exposure methods at same post-irradiation time in the same depth of cavity; the same lower-case superscript letters indicate no statistically significant differences between depths of cavity at same post-irradiation time in the same exposure method; the same upper-case superscript letters indicate no statistically significant differences between post-irradiation times at same depth of cavity in the same exposure method $(p>0.05)$

$\mathrm{KHN}=\mathrm{Knoop}$ hardness number

\begin{tabular}{|c|c|c|c|c|c|c|c|}
\hline \multirow[t]{2}{*}{ Exposure method } & \multirow{2}{*}{$\begin{array}{l}\text { Post- } \\
\text { irradiation } \\
\text { time }\end{array}$} & \multicolumn{6}{|c|}{ Depth of cavity (mm) } \\
\hline & & 0,5 & 2 & 4 & 6 & 8 & 10 \\
\hline \multirow{3}{*}{$\begin{array}{l}\text { Exposure time of } \\
20 \mathrm{~s}(20 \mathrm{~s})\end{array}$} & 0.5 hours & $43.48 \pm 0.56^{\alpha a c}$ & $39.89 \pm 0.92^{\alpha \mathrm{bc} C}$ & $37.56 \pm 0.40^{\alpha c c}$ & $35.89 \pm 0.73^{\alpha c d c}$ & $34.88 \pm 1.27^{\alpha \mathrm{dC}}$ & $33.08 \pm 1.71^{\alpha e c}$ \\
\hline & 24 hours & $45.76 \pm 0.74^{\alpha \mathrm{aB}}$ & $41.13 \pm 0.68^{\mathrm{abB}}$ & $39.39 \pm 0.32^{\alpha \subset B}$ & $39.19 \pm 0.31^{\alpha \subset A B}$ & $38.67 \pm 0.21^{\alpha \mathrm{CAB}}$ & $38.59 \pm 0.12^{\alpha \mathrm{CAB}}$ \\
\hline & 7 days & $46.79 \pm 0.59^{\alpha а A}$ & $42.94 \pm 0.59^{\alpha \mathrm{baA}}$ & $41.62 \pm 0.28^{\alpha \mathrm{bA}}$ & $40.03 \pm 1.14^{\alpha c A}$ & $39.62 \pm 1.28^{\alpha \subset A}$ & $39.04 \pm 1.07^{\alpha c A}$ \\
\hline \multirow{3}{*}{$\begin{array}{c}\text { Bonding }+ \\
\text { exposure time of } \\
20 \mathrm{~s}(\mathrm{~B}+20 \mathrm{~s})\end{array}$} & 0.5 hours & $41.71 \pm 0.54^{\mathrm{\beta aC}}$ & $38.63 \pm 0.60^{\alpha \mathrm{bc} c}$ & $37.67 \pm 0.58^{\mathrm{abcc}}$ & $37.07 \pm 0.58^{\alpha c C}$ & $35.49 \pm 0.98^{\alpha \mathrm{dB}}$ & $35.01 \pm 0.90^{\alpha \mathrm{dB}}$ \\
\hline & 24 hours & $46.11 \pm 0.59^{\alpha а a в}$ & $43.18 \pm 0.75^{\mathrm{\beta bB}}$ & $41.84 \pm 0.62^{\beta C B}$ & $41.70 \pm 0.49^{\beta с B}$ & $41.34 \pm 0.82^{\beta C A}$ & $41.17 \pm 0.84^{\beta c A}$ \\
\hline & 7 days & $47.50 \pm 0.25^{\mathrm{\alpha aA}}$ & $45.51 \pm 0.95^{\mathrm{BbA}}$ & $43.34 \pm 0.83^{\text {BCA }}$ & $43.35 \pm 0.88^{\mathrm{BCA}}$ & $42.54 \pm 0.70^{\text {BCA }}$ & $42.24 \pm 0.90^{\beta C A}$ \\
\hline \multirow{3}{*}{$\begin{array}{l}\text { Exposure time of } \\
\qquad 40 \mathrm{~s}(40 \mathrm{~s})\end{array}$} & 0.5 hours & $48.83 \pm 0.36^{\mathrm{yaB}}$ & $44.42 \pm 0.33^{\beta b C}$ & $42.83 \pm 0.50^{\beta c C}$ & $40.83 \pm 0.87^{\beta d C}$ & $38.60 \pm 0.58^{\beta e C}$ & $37.57 \pm 0.29^{\mathrm{BfC}}$ \\
\hline & 24 hours & $51.89 \pm 0.61^{\text {BaA }}$ & $49.04 \pm 0.66^{\mathrm{YbAB}}$ & $47.57 \pm 0.57$ УсАВ & $46.73 \pm 0.46^{\vee С А B}$ & $44.76 \pm 0.59$ \dAB & $43.98 \pm 0.58^{\text {ydAB }}$ \\
\hline & 7 days & $52.30 \pm 0.53^{\text {BaA }}$ & $49.47 \pm 0.52^{\mathrm{vbA}}$ & $47.92 \pm 0.76^{\text {rcA }}$ & $47.03 \pm 0.51^{\mathrm{rcA}}$ & $45.36 \pm 0.68^{\text {ydA }}$ & $44.76 \pm 0.77 \mathrm{VdA}$ \\
\hline \multirow{3}{*}{$\begin{array}{l}\text { Exposure time of } \\
120 \mathrm{~s}(120 \mathrm{~s})\end{array}$} & 0.5 hours & $48.57 \pm 0.51^{\mathrm{vac}}$ & $48.74 \pm 0.40^{\mathrm{vac}}$ & $48.84 \pm 0.34^{\mathrm{rac}}$ & $48.95 \pm 0.26^{\mathrm{vac}}$ & $48.98 \pm 0.15^{\mathrm{vac}}$ & $48.90 \pm 0.26^{\mathrm{yac}}$ \\
\hline & 24 hours & $52.40 \pm 0.25^{ß а \mathrm{~B}}$ & $52.35 \pm 0.27^{\bar{\sigma} a \mathrm{~B}}$ & $52.20 \pm 0.24^{\bar{a} \mathrm{aB}}$ & $52.40 \pm 0.28^{\delta \mathrm{aB}}$ & $52.67 \pm 0.26^{\bar{\delta} \mathrm{aB}}$ & $52.26 \pm 0.50^{\delta ̄ a B}$ \\
\hline & 7 days & $53.06 \pm 0.19^{\beta a A}$ & $53.03 \pm 0.21^{\overline{\sigma a A}}$ & $52.98 \pm 0.09^{\text {баA }}$ & $53.00 \pm 0.28^{\delta \mathrm{aA}}$ & $53.27 \pm 0.33^{\text {баA }}$ & $52.92 \pm 0.26^{\delta \mathrm{a} A}$ \\
\hline
\end{tabular}


Table 2- Mean $\mathrm{KHN} \pm \mathrm{SD}$ for $\mathrm{KHN}$ for Unifil Core EM (UCE) at 6 depths of cavity after 3 post-irradiation times by 4 lightexposure methods

The same lower-case superscript Greek characters indicate no statistically significant differences between exposure methods at same post-irradiation time in the same depth of cavity; the same lower-case superscript letters indicate no statistically significant differences between depths of cavity at same post-irradiation time in the same exposure method; the same upper-case superscript letters indicate no statistically significant differences between post-irradiation times at same depth of cavity in the same exposure method ( $p>0.05)$

$\mathrm{KHN}=\mathrm{Knoop}$ hardness number

\begin{tabular}{|c|c|c|c|c|c|c|c|}
\hline \multirow[t]{2}{*}{ Exposure method } & \multirow{2}{*}{$\begin{array}{l}\text { Post- } \\
\text { irradiation } \\
\text { time }\end{array}$} & \multicolumn{6}{|c|}{ Depth of cavity $(\mathrm{mm})$} \\
\hline & & 0,5 & 2 & 4 & 6 & 8 & 10 \\
\hline \multirow{3}{*}{$\begin{array}{l}\text { Exposure time of } \\
20 \mathrm{~s}(20 \mathrm{~s})\end{array}$} & 0.5 hours & $36.26 \pm 1.31^{\mathrm{\alpha ac}}$ & $34.18 \pm 0.97^{\mathrm{abc}}$ & $32.99 \pm 0.64^{\alpha b c}$ & $31.69 \pm 0.64^{\alpha \mathrm{cc}}$ & $29.10 \pm 0.49^{\alpha d C}$ & $27.31 \pm 0.39^{\alpha \mathrm{eC}}$ \\
\hline & 24 hours & $41.22 \pm 0.81^{\alpha \mathrm{aB}}$ & $38.42 \pm 1.14^{\alpha \mathrm{bBB}}$ & $38.35 \pm 1.07^{\alpha \mathrm{bBB}}$ & $38.42 \pm 1.19^{\alpha \mathrm{bB}}$ & $37.42 \pm 1.33^{\alpha \mathrm{bB}}$ & $36.87 \pm 1.50^{\alpha \mathrm{bB}}$ \\
\hline & 7 days & $42.86 \pm 0.80^{\alpha \mathrm{A} A}$ & $40.52 \pm 1.04^{\mathrm{\alpha bA}}$ & $39.79 \pm 1.20^{\mathrm{abcA}}$ & $39.56 \pm 1.15^{\mathrm{\alpha bcA}}$ & $38.37 \pm 1.01^{\alpha c A}$ & $38.08 \pm 1.23^{\alpha c A}$ \\
\hline \multirow{3}{*}{$\begin{array}{c}\text { Bonding }+ \\
\text { exposure time of } \\
20 \mathrm{~s}(\mathrm{~B}+20 \mathrm{~s})\end{array}$} & 0.5 hours & $32.23 \pm 0.97^{\mathrm{BaC}}$ & $30.78 \pm 0.79^{\beta b C}$ & $30.58 \pm 0.65^{\beta b C ~}$ & $30.54 \pm 0.47^{\beta b C}$ & $30.10 \pm 0.93^{\mathrm{abc}}$ & $29.49 \pm 0.79^{\beta c C}$ \\
\hline & 24 hours & $40.12 \pm 0.76^{\mathrm{\alpha aB}}$ & $37.97 \pm 1.08^{\alpha \mathrm{bB}}$ & $37.56 \pm 0.25^{\mathrm{\alpha bcB}}$ & $37.50 \pm 0.11^{\mathrm{abcB}}$ & $37.39 \pm 0.21^{\alpha b c B}$ & $36.79 \pm 0.42^{\alpha \mathrm{cB}}$ \\
\hline & 7 days & $42.06 \pm 0.40^{\alpha \mathrm{aA}}$ & $40.21 \pm 0.28^{\alpha \mathrm{bA}}$ & $39.08 \pm 0.24^{\alpha c A}$ & $39.19 \pm 0.26^{\alpha c A}$ & $38.82 \pm 0.26^{\alpha c \mathrm{~A}}$ & $38.09 \pm 0.43^{\alpha \mathrm{dA}}$ \\
\hline \multirow{3}{*}{$\begin{array}{l}\text { Exposure time of } \\
\qquad 40 \mathrm{~s}(40 \mathrm{~s})\end{array}$} & 0.5 hours & $37.19 \pm 0.24^{\mathrm{rac}}$ & $36.50 \pm 0.37 \mathrm{vac}$ & $35.28 \pm 1.15^{\mathrm{ybB}}$ & $34.14 \pm 0.61$ rcc & $32.22 \pm 0.17^{\mathrm{\beta dB}}$ & $30.36 \pm 0.13^{\mathrm{vec}}$ \\
\hline & 24 hours & $42.31 \pm 0.38^{\text {аав }}$ & $40.93 \pm 0.53^{\beta ь B}$ & $40.90 \pm 0.61^{\mathrm{BbA}}$ & $40.62 \pm 0.49^{\mathrm{BbcB}}$ & $39.80 \pm 1.10^{\beta b C A}$ & $39.51 \pm 0.87^{\text {ВС }}$ \\
\hline & 7 days & $43.07 \pm 0.15^{\mathrm{BaA}}$ & $42.12 \pm 0.45^{\mathrm{BbA}}$ & $41.87 \pm 0.45^{\mathrm{BbA}}$ & $41.97 \pm 0.47^{\mathrm{BDA}}$ & $40.76 \pm 0.61^{\mathrm{BCA}}$ & $40.77 \pm 0.69^{\mathrm{BCA}}$ \\
\hline \multirow{3}{*}{$\begin{array}{l}\text { Exposure time of } \\
120 \mathrm{~s}(120 \mathrm{~s})\end{array}$} & 0.5 hours & $37.35 \pm 0.32^{\mathrm{vac}}$ & $37.60 \pm 0.35^{\overline{\delta a c}}$ & $37.46 \pm 0.25^{\mathrm{\delta ac}}$ & $37.59 \pm 0.18^{\bar{\delta} а в}$ & $37.36 \pm 0.21^{\mathrm{vac}}$ & $37.32 \pm 0.25^{\text {бав }}$ \\
\hline & 24 hours & $42.58 \pm 0.30^{\text {вав }}$ & $42.67 \pm 0.62^{\text {уаАв }}$ & $42.60 \pm 0.46^{\text {vаАв }}$ & $42.59 \pm 0.46^{\mathrm{vaA}}$ & $42.62 \pm 0.55^{\text {гаАв }}$ & $42.7 \pm 0.44^{\mathrm{raA}}$ \\
\hline & 7 days & $42.78 \pm 0.40^{\mathrm{Ba}}$ & $42.98 \pm 0.77^{\mathrm{vaA}}$ & $42.97 \pm 0.86^{\mathrm{vaA}}$ & $42.81 \pm 0.45^{\mathrm{raA}}$ & $43.00 \pm 0.85^{\mathrm{raA}}$ & $43.06 \pm 0.60^{\text {raA }}$ \\
\hline
\end{tabular}

For DCP, with the B+20 s method, no significant differences in the KHN values were observed at 0.5 hours post-irradiation at all depths of cavity, except $0.5 \mathrm{~mm}(\mathrm{p}>0.05)$. However, at 24 hours and 7 days post-irradiation, the $\mathrm{B}+20 \mathrm{~s}$ method resulted in significantly higher $\mathrm{KHN}$ values than the $20 \mathrm{~s}$ method at all depths of cavity, except 0.5 $\mathrm{mm}(\mathrm{p}<0.05)$. On the other hand, for UCE, at 0.5 hours post-irradiation, the $B+20 \mathrm{~s}$ method showed significantly lower KHN values than the 20 s method up to the depth of $6.0 \mathrm{~mm}$; however, the KHN values were significantly higher at the depths of $8.0 \mathrm{~mm}$ and $10.0 \mathrm{~mm}(\mathrm{p}<0.05)$. At 24 hours and 7 days post-irradiation, no significant differences in $\mathrm{KHN}$ values were observed between the $B+20 s$ and 20 $s$ method at all depths of cavity $(p>0.05)$.

For all light-exposure methods, except the $120 \mathrm{~s}$ method, the UCE exhibited significantly higher KHN values at all depths of cavity, except at $4.0 \mathrm{~mm}$ in the $40 \mathrm{~s}$ method, at 7 days post-irradiation than at 0.5 hours and 24 hours post-irradiation $(p<0.05)$. It was found that the KHN values of DCP were significantly higher than those of UCE at all depths of cavity and post-irradiation times, regardless of the exposure method $(p<0.05)$.

\section{DISCUSSION}

The results of this study indicate that the KHNs of dual-cured core build-up resin composites depend on the light-exposure method, including irradiation duration, use of bonding agent, depth of cavity, post-irradiation time, and material brand. Therefore, the research hypotheses formulated for this study must be rejected.

$\mathrm{KHN}$ has been shown to be a good indicator of the degree of conversion/polymerization based on its good correlation with infrared spectroscopy ${ }^{9,10,31}$. However, the prediction of an absolute value of degree of conversion by means of an absolute hardness value is not achievable, since other factors such as type and size of filler, filler load, monomer composition, quantity of initiators, and the ratio of chemical- and light-cured components strongly influence the final quantity of reacted monomers ${ }^{2,5,14}$. Microhardness data from the same resin cement only should be compared according to the depth of the root canal or time elapsed since luting ${ }^{3}$. KHNs could be used to reflect the degree of conversion at different depths of a resin composite $^{32}$. Therefore, KHNs were measured in the present study to reflect monomer conversion at different depths of cavity and post-irradiation times in the dual-cured core build-up resin composites.

The KHNs of both core build-up resin composites irradiated for 20 or 40 seconds were the highest at the depth of $0.5 \mathrm{~mm}$, and gradually decreased with increasing depth. This phenomenon could 
be simply attributed to the direction of photoinitiation. Light irradiation was focused on the top surface of the cavity. Therefore, polymerization of the resin composites, by means of photoactivated free radicals, may occur immediately at the shallow depths of cavity. This finding, that is, KHN of light- and dual-cured resin composites are affected by depth of cavity, has been reported previously ${ }^{4,6-8}$. The chemical-curing mechanism of dual-cured resin composites is usually based on a redox reaction of benzoyl peroxide with aromatic tertiary amines, which generates free radicals that break the aliphatic carbon double bonds to initiate the polymerization process. It is supposed that immediate photo-activation after light irradiation, despite causing a rapid increase in the viscosity of the polymer matrix, does not hinder migration of the activated free radicals responsible for further chemically induced polymerization. Although the photo-activated free radicals at shallow depths of cavity could induce chain propagation of the resin polymer in the downward direction, the exact polymerization mechanism of dual-cured core build-up resin composite at greater depths of cavity remains unknown. It is difficult to distinguish clearly between the depths of cavity at which polymerization of the resin composite occurs through photo-initiation and those at which polymerization occurs by means of chemical initiation alone.

Evaluation of the duration of photo-activation revealed that a longer exposure time of 40 seconds resulted in significantly higher $\mathrm{KHN}$ values than did a shorter exposure time of 20 seconds at all depths of cavity and post-irradiation times for both resin composites; however, this trend was not observed in UCE at the depth of $0.5 \mathrm{~mm}$. Thus, our study showed that prolonged irradiation durations resulted in increased hardness values. Light-curing units with lower power density needed longer light-exposure times to produce a similar microhardness value of resin composite as that of light sources with high power density ${ }^{11}$. Therefore, with longer light-exposure durations, which result in higher energy densities at a given irradiance, more photo-sensitizer molecules are activated, which in turn increase the free radical concentration and consequently the conversion of double bonds. However, at the depth of $0.5 \mathrm{~mm}$, no significant differences were observed in the KHN values between the light-irradiation durations of 40 seconds and 120 seconds ( 40 seconds each on the top and either side of the cavity) for both resin composites. This finding might be attributed to the fact that the polymer network developed during light exposure for 40 seconds does not allow any additional mobility of the polymer chains in order to increase monomer conversion, indicating that the light-irradiation duration of 40 seconds alone is sufficient.

Dentin hardness ranges from KHN values of 50 to 70, depending on the distance from the amelodentinal junction ${ }^{21}$. The mean microhardness (KHN) value of 52.9 for DCP with $120 \mathrm{~s}$ method at the depth of $10.0 \mathrm{~mm}$ at 7 days post-irradiation therefore predicts similar mechanical properties to that of dentin. The equal degree of polymerization within the core material may support a uniform distribution of stress along the tooth-material interface under load. Longer light-exposure durations result in superior microhardness, but, at the same time, contribute to an increase of shrinkage and contraction stress of the dualcured core build-up resin composite ${ }^{38}$. In cases of significant coronal destruction, it is necessary to replace the lost tooth structure with a core buildup material to attain full-coverage restoration. The cast post and core, prefabricated post and core materials, and coronal-radicular build-ups are the available options for this purpose. The fracture resistance and survival probability of post and core restorations depend on several factors such as the post material, luting agent, amount and condition of residual tooth structure, core material, preparation of the tooth for restorative procedures, and, finally, the fixed restoration ${ }^{16,22,25,34}$. Therefore, when using dual-cured core build-up resin composites, it is preferable to prepare the composites by using the effective exposure method.

Before core build-up resin composites are used, a bonding agent must be applied on the cavity wall. The effectiveness of the bonding agent on the $\mathrm{KHN}$ as an indirect method of monomer conversion differed between the 2 resin composites. For DCP, at 24 hours and 7 days post-irradiation, application of the bonding agent resulted in significantly higher KHNs than the 20 s method at all depths of cavity; however, this was not observed with UCE. The initiator and/or accelerator present in the bonding agent would promote monomer conversion of the dual-cured core build-up resin composites. On the other hand, the acidic monomer in the bonding agent inhibits the amine co-initiator in the dualcured materials ${ }^{16}$, which in turn adversely affects polymerization of dual-cured core build-up resin composites. To prevent this inhibitory effect, aromatic sulfinic acid sodium salts are sometimes added to the bonding agent ${ }^{15,37}$. The differences in compositions between the 2 core build-up resin composites might be responsible for the difference in their KHN behaviors.

In the present study, both resin composites at all depths of cavity had a post-curing effect 7 days after irradiation, showing statistically higher KHN values than those at 0.5 hours post-irradiation for all light-exposure methods. These results are 
consistent with those of a previous study ${ }^{3}$, but not with those of another study ${ }^{41}$, which did not find changes in microhardness values 24 hours after irradiation. However, the polymerization reaction of the dual-cured materials might be specific ${ }^{19}$, and these previous studies used resin cements, whereas dual-cured core build-up resin composites were used in the present study. In fact, in the former study, neither did the authors evaluate dual-cured core build-up resin composites nor did they evaluate hardness behavior of dual-cured core build-up resin composite in simulated depths of cavity.

Dual-cured resin composites have been introduced for use as both luting and core buildup materials. Superior physical properties are important for a successful restoration. In this study, it was found that the KHNs of DCP were superior to those of UCE, regardless of exposure methods. Various factors can influence the microhardness of a resin composite, such as filler load, type, or size, or resin matrix type ${ }^{17,18}$. Increasing the monomer viscosity decreased the hardness ${ }^{27}$. In this study, the association between $\mathrm{KHN}$ values of the resin composite and composition of filler and matrix resin was not evaluated. On the other hand, the differences between the KHNs at the depths of $0.5 \mathrm{~mm}$ and $10.0 \mathrm{~mm}$ in UCE were lower than those in DCP, regardless of the light-exposure method. Dual-cured materials differ markedly in terms of the relative content of light- and selfactivated catalysts ${ }^{13}$. Differences in the degree of conversion among materials when subjected to various curing protocols may consequently be attributed to variations in catalyst systems. In the present study, since similar KHNs were observed irrespective of the light-exposure method at greater depths of cavity in UCE rather than DCP, it might be inferred that the former exhibits high levels of chemically curing activators compared with the latter, compensating for attenuation of light energy at greater depths of cavity. Indeed, the polymerization behavior of dual-cured resin composites is strongly related to the material and can vary as a function of composition ${ }^{35}$. The speed of the polymerization reaction is strongly influenced by inhibitor concentration in the unfilled light-cured methacrylate-based systems ${ }^{30}$. Therefore, the curing mechanism of a specific composite material may not be applicable to other materials.

\section{CONCLUSIONS}

Within the limitations of the present study, the following conclusions can be drawn:

1. The microhardness of the dual-cured core build-up resin composites vary depending on the light-exposure method, including irradiation duration, use of bonding agent, depth of cavity, post-irradiation time, and material brand.

2. For both resin composites, irradiation for 120 seconds does not result in significant differences in KHNs among all 6 depths of cavity at all postirradiation times.

3. Based on the physical property of microhardness behavior, dual-cured core build-up resin composites are preferably prepared by the effective exposure method.

\section{REFERENCES}

1- Aksornmuang J, Nakajima M, Foxton RM, Tagami J. Mechanical properties and bond strength of dual-cure resin composites to root canal dentin. Dent Mater. 2007;23:226-34.

2- Arrais CA, Giannini M, Rueggeberg FA. Kinetic analysis of monomer conversion in auto- dual-polymerizing modes of commercial resin luting cement. J Prosthet Dent. 2009;101:12836.

3- Baena E, Fuentes MV, Garrido MA, Rodríguez J, Ceballos L. Influence of post-cure time on the microhardness of self-adhesive resin cements inside the root canal. Oper Dent. 2012;37:548-56. 4- Bouschlicher MR, Rueggeberg FA, Wilson BM. Correlation of bottom-to-top surface microhardness and conversion ratios for a variety of resin composite compositions. Oper Dent. 2004;29:698704.

5- Cadenaro M, Navarra CO, Antoniolli F, Mazzoni A, Di Lenarda, Rueggeberg FA, et al. The effect of curing mode on extent of polymerization and microhardness of dual-cured, self-adhesive resin cements. Am J Dent. 2010;23:14-8.

6- Camargo EJ, Moreschi E, Baseggio W, Cury JA, Pascotto RC. Composite depth of cure using four polymerization techniques. J Appl Oral Sci. 2009;17:446-50.

7- Ciccone-Nogueira JC, Borsatto MC, Souza-Zaroni WC, Ramos RP, Palma-Dibb RG. Microhardness of composite resins at different depths varying the post-irradiation time. J Appl Oral Sci. 2007;15:305-9.

8- Cunha LG, Sinhoreti MA, Consani S, Sobrinbo LC. Effect of different photoactivation methods on the polymerization depth of a light-activated composite. Oper Dent. 2003;28:155-9.

9- DeWald JP, Ferracane JL. A comparison of four modes of evaluating depth of cure of light-activated composites. J Dent Res. 1987;66:727-30.

10- Ferracane JL. Correlation between hardness and degree of conversion during the setting reaction of unfilled dental restorative resins. Dent Mater. 1985;1:11-4.

11- Franco EB, Santos PA, Mondelli RF. The effect of different lightcuring units on tensile strength and microhardness of a composite resin. J Appl Oral Sci. 2007;15:470-4.

12- Galhano GA, Melo RM, Barbosa SH, Zamboni SC, Bottino MA, Scotti R. Evaluation of light transmission through translucent and opaque post. Oper Dent. 2008;33:321-4.

13- Hasegawa EA, Boyer DB, Chan DC. Hardening of dualcured cements under composite resin inlays. J Prosthet Dent. 1991;66:187-92.

14- Hofmann N, Papshart G, Hugo B, Klaiber B. Comparison of photo-activation versus chemical or dual-curing of resin-based luting cements regarding flexural strength, modulus and surface hardness. J Oral Rehabil. 2001;28:1022-8.

15- Ikemura K, Endo T. Effect on adhesion of new polymerization initiator systems comprising 5-monosubstituted barbituric acids, aromatic sulfinate amides, and tert-butyl peroxymaleic acid in dental adhesive resin. J Appl Polym Sci. 1999;72:1655-68.

16- Kalkan M, Usumez A, Oztuk AN, Belli S, Eskitasciogiu G. Bond strength between root dentin and three glass-fiber post systems. J Prosthet Dent. 2006;96:41-6. 
17- Kim KH, Ong JL, Okuno O. The effect of filler loading and morphology on the mechanical properties of contemporary composites. J Prosthet Dent. 2002;87:642-9.

18- Li Y, Swartz ML, Phillips RW, Moore BK, Roberts TA. Effect of filler content and size on properties of composites. J Dent Res. $1985 ; 64: 1396-401$.

19- Lu H, Mehmood A, Chow A, Powers JM. Influence of polymerization mode on flexural properties of esthetic resin luting agents. J Prosthet Dent. 2005;94:549-54.

20- Lutz F, Krejci I, Oldenburg TR. Elimination of polymerization stresses at the margins of posterior composite resin restorations: a new restorative technique. Quintessence Int. 1986;17:777-84. 21- Meredith N, Sherriff M, Setchell DJ, Swanson SA. Measurement of the microhardness of human enamel and dentine using an indentation technique. Arch Oral Biol. 1996;41:539-45.

22- Naumann M, Metzdorf G, Fokkinga W, Watzke R, Sterzenbach $G$, Bayne $S$, et al. Influence of test parameters on in vitro fracture resistance of post-endodontic restorations: a structured review. J Oral Rehabil. 2009;36:299-312.

23- Park J, Chang J, Ferracane J, Lee IB. How should composite be layered to reduce shrinkage stress: incremental or bulk filling? Dent Mater. 2008;24:1501-5.

24- Pegoraro TA, Silva NR, Carvalho RM. Cements for use in esthetic dentistry. Dent Clin North Am. 2007;51:453-71.

25- Peroz I, Blankenstein F, Lange KP, Naumann M. Restoring endodontically treated teeth with posts and cores - a review. Quintessence Int. 2005;36:737-46.

26- Plasmans PJ, Creugers NH, Mulder J. Long-term survival of extensive amalgam restorations. J Dent Res. 1998;77:453-60.

27- Podgórski M. Structure-property relationship in new photo-cured dimethacrylate-based dental resins. Dent Mater. 2012;28:398-409.

28- Ramos MB, Pegoraro TA, Pegoraro LF, Carvalho RM. Effects of curing protocol and storage time on the micro-hardness of resin cements used to lute fiber-reinforced resin posts. J Appl Oral Sci. 2012;20:556-62.

29- Roberts HW, Leonard DL, Vandewalle KS, Cohen ME, Charlton DG. The effect of a translucent post on resin composite depth of cure. Dent Mater. 2004;20:617-22.
30- Rosentritt M, Shortall AC, Palin WM. Dynamic monitoring of curing photoactivate resins: a methods comparison. Dent Mater. 2010;26:565-70.

31- Rueggeberg FA, Craig RG. Correlation of parameters used to estimate monomer conversion in a light-cured composite. J Dent Res. 1988;67:932-7.

32- Rueggeberg FA, Ergle JW, Mettenburg DJ. Polymerization depths of contemporary light-curing units using microhardness. J Esthet Dent. 2000;12:340-9.

33- Schwartz RS, Robbins JW. Post placement and restoration of endodontically treated teeth: a literature review. J Endod. 2004;30:289-301.

34- Stankiewicz NR, Wilson PR. The ferrule effect: a literature review. Int Endod J. 2002;35:575-81.

35- Stavridakis MM, Kalaboura AI, Krejci I. Degree of remaining $\mathrm{C}=\mathrm{C}$ bonds, polymerization shrinkage and stresses of dual-cured core build-up resin composites. Oper Dent. 2005;30:443-52. 36- Stavridakis MM, Lutz F, Johnston WM, Krejci I. Linear displacement and force induced by polymerization shrinkage of resin-based restorative materials. Am J Dent. 2003;16:431-8.

37- Suh Bi, Feng L, Pashley DH, Tay FR. Factors contributing to the incompatibility between simplified-step adhesives and chemically cured or dual-cured composites. Part III. Effect of acidic resin monomers. J Adhes Dent. 2003;5:267-82.

38- Tauböck TT, Bortolotto T, Buchalla W, Attin T, Krejci I. Influence of light-curing protocols on polymerization shrinkage and shrinkage force of a dual-cured core build-up resin composite. Eur J Oral Sci. 2010;118:423-9.

39- Tauböck TT, Buchalla W, Hiltebrand U, Roos M, Krejci I, Attin $\mathrm{T}$. Influence of the interaction of light- and self-polymerization on subsurface hardening of a dual-cured core build-up resin composite. Acta Odontol Scand. 2011;69:41-7.

40- Van Nieuwenhuysen JP, D'Hoore W, Carvalho J, Qvist V. Longterm evaluation of extensive restorations in permanent teeth. J Dent. 2003;31:395-405.

41- Yan YL, Kim YK, Kim KH, Kwon TY. Changes in degree of conversion and microhardness of dental resin cements. Oper Dent. 2010;35:203-10. 